\title{
COMPARATIVE STUDY BETWEEN LAPAROSCOPIC AND CONVENTIONAL BURCH COLPOSUSPENSION FOR TREATMENT OF GENUINE STRESS URINARY INCONTINENCE
}

\author{
Shafik M, MD, Amin H, MD, Swelam E, MD, Abdel Dayem H, MD, Abo El Fath A, MS \\ Obstetrics\&Gynecology department, Faculty of Medicine, Zagazig University
}

\begin{abstract}
Objective: To compare the efficacy and complications of laparoscopic and conventional approach for Burch colposuspension in treatment of stress urinary incontinence.

Study design: Prospective randomised trial.

Methods :After standered history and preoperative evaluation, groupA( $n=30)$ offered open Burch colposuspension and group B $(\mathrm{n}=30)$ had laparoscopic colposuspension.

Results: No significant differences regarding objective and subjective outcome of total 60 patients follow up at 1,6 and 12 months. More operative time found in group B $(92 \pm 5.2 \mathrm{~min})$ versus group A $(58.2 \pm 4.4 \mathrm{~min}), P$ $<0.001$. Laparoscopic approach was less in pain $(P<0.001)$ and hospital $\operatorname{stay}(P<0.001)$. No significant differences between both groups regarding intraoperative and post operative complications .

Conclusion: Although laparoscopic burch offers an alternative to conventional burch with shorter hospital stay, less postoperative pain and quicker recovery, but still it has its drawbacks. It needs long learning curve and has prolonged operative time.
\end{abstract}

\section{INTRODUCTION}

$S^{t}$ tress urinary incontinence (SUI) affects about $10 \%$ to $30 \%$ of females between the ages of 15 and 64 year (1). This prevalence is mostly underestimated as many women with SUI suffer in silence $(2,3)$. SUI is defined as the involuntary leakage of urine on effort or exertion or on sneezing or coughing, in absence of detrosur contraction (4). More than 200 procedures designed for treatment of urinary incontinence have been described in the medical literature (5). Burch et al, 1968 described the retropubic colposuspension for management of SUI (6). Many operative procedures traditionally performed by laparotomy can now be done with laparoscopy (7). Laparoscopic colposuspension was first described by Vancaillie and Schuessler in 1991(8). Our study aimed to compare the efficacy and complications of laparoscopic and conventional approach for Burch colposuspension in treatment of stress urinary incontinence.

Material \& Methods: This study was conducted in the Department of Obstetrics and Gynecology, Faculty of Medicine, Zagazig University during the period from October 2010 to December 2014. Sixty patients complaining of stress urinary incontinence with failed trial of pelvic floor muscle training were selected from those attending the Obstetrics and Gynecology and
Urology Outpatient Clinics. Patients with previous incontinence surgery, neurogenic bladder, detrusor overactivity, urinary tract infection, or morbid obesity were excluded from the study. Written consent was obtained from all patients after full explanation of benefits and hazards of the surgical procedure that was performed for each patient, before getting them involved in the study. Confidentiality of all data and tests of the studied population was preserved.

Patients were randomized in to two groups thirty patients in each, (group A) \& (group B). All patients had preoperative evaluation that included: standard history taking, physical examination, and bladder stress test. One hour pad test was done for objective assessment of severity of incontinence. Urodynamic studies were done mainly to exclude cases with detrosur overactivity.

Using a low Pfannenstiel incision Group A offered open (conventional) Burch colposuspension with application of two sutures in each side with minimal tension, (polypropylene 0, Ethicon). For group B a $10 \mathrm{~mm}$ laparoscope, with video camera, was introduced through the umbilical trocar. Another $10 \mathrm{~mm}$ in left lateral and two $5 \mathrm{~mm}$ trocars in right lateral and suprapubic areas were introduced. The larger trocar was needed to accommodate the passage of needles and into the abdomen. Spacing of trocars 
sufficiently from each other was needed to facilitate laparoscopic suturing. Transperitoneal approach to retropubic space was used. Two sutures were applied on each side as group A. Sutures were tied with intracorporeal technique.

All cases in both groups received Diclofinac potassium $100 \mathrm{mg}$ and mepridine hydrochloride $50 \mathrm{mg}$ intramuscular with anaethesia recovery and 12 hours later second dose of diclofinac potassium was given. Also 40-60 mg Enoxaparin was given 6-12 hours postoperatively as SC injections. Foley's catheter was removed 24 hours postoperative. If patient had difficult voiding or urine retention, catheter was re-inserted and we gave the patient appointment in the clinic one week later for a repeat trial of voiding.

Patients were discharged, once they were tolerating regular diet, walk independently, and after adequate control of post operative pain.

The primary outcome was assessment of cure objectively and subjectively at 1, 6 and 12 months after the procedure. Objective cure was a negative 1-hour pad test, and a subjective cure was the response of 'happy or pleased' to the question (how would you feel?). The secondary outcomes includes: Operative time, intra operative blood loss, Hospital stay, Operative morbidity as return to theatre or Bladder injury, voiding difficulties, Wound infection, Urine infection . Post operative pain was measured by Pain score through 12 hours postoperative period according to revised face pain scale (9).

Data collected and outcome measures coded, entered and analyzed using Microsoft Excel software. Data were then imported into Statistical Package for the Social Sciences (SPSS version 20.0) (Statistical Package for the Social Sciences) software for analysis. According to the type of data, the following tests were used to test differences for significance. Differences between frequencies (qualitative variables) and percentages in groups were compared by Chi-square test. Differences between means (quantitative variables) in two paired parametric group by paired $\mathrm{t}$ test. $\mathrm{P}$ value was set at $<0.05$ for significant results \& $<0.001$ for high significant result.

\section{RESULTS}

Table (1): preoperative patients characteristics

\begin{tabular}{|c|c|c|c|c|}
\hline & Group A & Group B & & \multirow{2}{*}{ P-value } \\
\hline & (n) $\%$ & (n) $\%$ & & \\
\hline Age in years & & & $X^{2} / t$ & \\
\hline$>50$ & $30.0 \%$ & $23.3 \%$ & 0.34 & 0.55 \\
\hline$<50$ & (21) $70.0 \%$ & (23) $76.7 \%$ & & \\
\hline Mean \pm SD & $43.8 \pm 5.8$ & $44.7 \pm 6.7$ & 0.38 & 0.52 \\
\hline Parity & & & $\mathbf{X}^{2}$ & \\
\hline 1 & (2) $6.7 \%$ & (3) $10 \%$ & & \\
\hline 2 & (4) $13.3 \%$ & (5) $16.7 \%$ & 0.57 & 0.96 \\
\hline 3 & (12) $40 \%$ & (12) $40 \%$ & & \\
\hline 4 & (9) $30 \%$ & (8) $26.6 \%$ & & \\
\hline 5 & (3) $10 \%$ & (2) $6.7 \%$ & & \\
\hline BMI & & & $\mathbf{T}$ & \\
\hline Mean \pm SD & $26.5 \pm 2.5$ & $27.2 \pm 2.8$ & 0.71 & 0.3 \\
\hline Pad test & & & $\mathrm{X} 2$ & \\
\hline$<5 \mathrm{gm}$ & (6) $20.0 \%$ & (7) $23.3 \%$ & & \\
\hline $5-10 \mathrm{gm}$ & (4) $13.3 \%$ & (3) $10.0 \%$ & 0.36 & 0.94 \\
\hline $10.1-20 \mathrm{gm}$ & (4) $13.3 \%$ & (5) $16.7 \%$ & & \\
\hline$>20 \mathrm{gm}$ & (16) $53.4 \%$ & (15) $50.0 \%$ & & \\
\hline
\end{tabular}

Table (1) shows that no significant difference between both groups regarding preoperative patients characteristics. 
Table (2): Operative time and estimated blood loss

\begin{tabular}{ccccc}
\hline & \multicolumn{2}{c}{ Group A } & Troup B & P-value \\
\cline { 2 - 3 } & \multicolumn{2}{c}{$\begin{array}{c}\text { Mean } \pm \text { SD } \\
\text { (range) }\end{array}$} & & \\
\hline Intra-operative blood loss & $150.5 \pm 31.2$ & $135.3 \pm 29.9$ & 1.92 & 0.057 \\
$(\mathrm{~mL})$ & $(100-200)$ & $(80-180)$ & & \\
\hline Operative time (min) & $58.2 \pm 4.4$ & $92 \pm 5.2$ & 27.4 & $<0.001$ \\
& $(45-70)$ & $(65-100)$ & & \\
\hline
\end{tabular}

Table (2) shows that there was a highly significant difference in the operating time between both groups with the shorter time being observed in open group. The mean amount of blood loss in laparoscopy group was slightly less than the open group but without significance.

Table (3): Hospital stay and pain score

\begin{tabular}{ccccc}
\hline & Group A & Group B & T & P-value \\
\hline Hospital stay (hours) & \multicolumn{5}{c}{} \\
\hline Mean \pm SD & $95.4 \pm 11.1$ & $73.4 \pm 10.2$ & 5.8 & $<0.001$ \\
\hline Range & $75-110$ & $48-96$ \\
\hline Pain score & $6.8 \pm 1.4$ & $3.7 \pm 1.5$ & 5.2 & $<0.001$ \\
\hline Mean \pm SD & $2-8$ & $2-6$ & & \\
\hline Range & &
\end{tabular}

As shown in table (3), there was a high significant difference in the hospital stay between the 2 groups with longer hospital stay in group A. Also there was a high significant difference in the pain score between the 2 groups with the higher pain score observed in group A.

Table (4) complications

\begin{tabular}{|c|c|c|c|c|c|c|}
\hline & Group A & Group B & $\mathrm{X}^{2}$ & P-value & $\mathrm{X}^{2}$ & P-value \\
\hline Return to theatre & $0 \quad 0.0 \%$ & $0 \quad 0.0 \%$ & 0.0 & 1.0 & \multirow{5}{*}{1.45} & \multirow{5}{*}{0.69} \\
\hline Bladder injury & $0.0 \%$ & $3.3 \%$ & 1.6 & 0.2 & & \\
\hline Wound infection & $6.7 \%$ & $3.3 \%$ & 1.15 & 0.28 & & \\
\hline UTI & $6.7 \%$ & $10.0 \%$ & 0.65 & 0.41 & & \\
\hline Fever & $3.3 \%$ & $3.3 \%$ & 0.0 & 1.0 & & \\
\hline
\end{tabular}

As shown in table (4), there was no statistically significant difference in the incidence of intraoperative or postoperative complications.

Table(5) post operative urinary problems

\begin{tabular}{ccccccc}
\hline & \multicolumn{2}{c}{ Group A } & \multicolumn{2}{c}{ Group B } & $\mathbf{X}^{\mathbf{2}}$ & P-value \\
\hline Retention & 1 & $3.3 \%$ & 1 & $3.3 \%$ & 0.0 & 1.0 \\
\hline Difficult voiding & 3 & $10.0 \%$ & 5 & $16.7 \%$ & 1.38 & 0.23 \\
\hline Urgency & 3 & $10.0 \%$ & 4 & $13.3 \%$ & 0.39 & 0.53 \\
\hline
\end{tabular}

Regarding post operative urinary problems there was no significant difference between both groups as shown in table (5)

Table(6) Objective assessment by one hour pad test

\begin{tabular}{ccccccc}
\hline & Group A & \multicolumn{2}{c}{ Group B } & $\mathbf{X}^{2}$ & P-value \\
\hline 1 month & 24 & $80.0 \%$ & 22 & $73.3 \%$ & 0.32 & 0.57 \\
\hline 6 months & 26 & $86.6 \%$ & 24 & $80.0 \%$ & 0.21 & 0.64 \\
\hline 12 months & 26 & $86.6 \%$ & 25 & $83.3 \%$ & 0.05 & 0.81 \\
\hline
\end{tabular}

Regarding success rate assessed objectively by one hour pad test Table (6) shows no significant difference between both groups during 1, 6 and 12 months follow up. 
Table (7) patient satisfaction

\begin{tabular}{|c|c|c|c|c|c|c|c|}
\hline \multirow{2}{*}{1 month } & \multirow[b]{2}{*}{ Satisfied } & \multicolumn{2}{|c|}{ Group A } & \multicolumn{2}{|c|}{ Group B } & \multirow{2}{*}{$\frac{\mathbf{X}^{\mathbf{2}}}{0.3}$} & \multirow{2}{*}{$\frac{\text { P-value }}{0.58}$} \\
\hline & & (19) & $63.3 \%$ & $(21)$ & $70.0 \%$ & & \\
\hline & unsatisfied & (11) & $36.7 \%$ & (9) & $30.0 \%$ & & \\
\hline \multirow[t]{2}{*}{6 month } & Satisfied & $(20)$ & $66.7 \%$ & $(23)$ & $76.7 \%$ & 0.73 & 0.38 \\
\hline & unsatisfied & (10) & $33.3 \%$ & (7) & $23.3 \%$ & & \\
\hline \multirow[t]{2}{*}{12 month } & Satisfied & (23) & $76.7 \%$ & $(25)$ & $83.3 \%$ & 0.41 & 0.51 \\
\hline & unsatisfied & (7) & $23.3 \%$ & (5) & $16.7 \%$ & & \\
\hline \multicolumn{2}{|c|}{$\mathrm{X}^{2}$} & \multicolumn{2}{|c|}{1.34} & \multicolumn{2}{|c|}{1.49} & & \\
\hline \multicolumn{2}{|c|}{ P-value } & \multicolumn{2}{|c|}{0.51} & \multicolumn{2}{|c|}{0.47} & & \\
\hline
\end{tabular}

No significant difference between both groups regarding patient satisfaction during follow up at 1 , 6 and 12 months follow up as shown in table (7).

\section{DISCUSSION}

In this study, it was tried to investigate the benefits of using Laparoscopic colposuspension in management of urodynamic stress incontinence in comparison with open technique.

As shown in table (2), there was a highly significant difference in the operating time between both groups with the shorter time being observed in group A. Open technique took $58.2 \pm 4.4$ minutes, while laparoscopic approach took $92 \pm 5.2$ minutes. This can be explained by technical difficulty of laparoscopic suturing, and approaching retropubic space. The mean operative time for laparoscopic colposuspension in our study was similar to that reported by Carey et al (87 minutes) (10) and Miannay et al (89 minutes) (11). On the other hand, it was longer than that reported by Persson \& Hanssen (60 minutes) (12), this may be due to placing only one suture on each side and also longer than Bulent M. et al (46 minutes) (13) and this may be due to using extraperitoneal approach. While it was shorter than Walter et al. (189 minutes)(14). this could be due to concurrent vaginal prolapse repair.

As regards the mean amount of estimated blood loss in the group A was insignificantly higher $(150.5 \pm 31.2)$ than group B (135.3 \pm 29.9$)$. That was shown in table (2) .In blood loss there is a wide variation between the literatures. Our results coincide with the results of Polascik et al who found the mean amount of blood loss $108 \mathrm{~mL}$ (20-
$300)$ in laparoscopy group and $153 \mathrm{~mL}$ (50400 ) in the open group which is also statistically insignificant. (15) While Carey et al found significant difference between both groups with more mean blood loss in open group $(170 \mathrm{~mL})$ than laparoscopic group (126 mL) (10). Also the results of Ankardal et al show that open group $(105 \mathrm{~mL})$ significantly more than laparoscopic one ( $35 \mathrm{~mL})(16)$. On the other hand the mean amount of blood loss was insignificantly more in the laparoscopy group $(270 \mathrm{~mL})$ than the open group $(240 \mathrm{~mL})$ according to Walter et al. (14).

Table (3) shows that the mean duration of hospital stay in group A was significantly longer $(95.4 \pm 11.1$ hours $)$ than that in the group B $(73.4 \pm 10.2$ hours $)$. This significant difference was noticed in most of the studies in the literature. That was expected as laparoscopic approach had less post operative pain and rapid recovery. Our results coincide with the results of Miannay et al. (11) Who found the mean duration of hospital stay 160.8 hours in open group and 72 hours in laparooscopy group which is also statistically significant. While Carey et al. found insignificant difference between both groups with more mean duration of hospital stay in open group (93.6 hours) than laparoscopic group (88.8 hours) (10). Our results in laparoscopic group regarding hospital stay was more than Bulent et al. who compared between transperitoneal and extraperitoneal laparoscopic approach with 


\section{(43.2 hours) and ( 37.6 hours)} respectively.(13)

In our study all patients in both groups received Diclofinac potassium $100 \mathrm{mg}$ and mepridine hydrochloride $50 \mathrm{mg}$ intramuscular with anaethesia recovery and 12 hours later second dose of diclofinac potassium was given .The pain score; using the revised faces pain scale; in both groups shows a significant difference. With higher score in group A (6.8 $\pm 1.4)$ than group $B(3.7 \pm 1.5)$ table (3). That coincides with Carey et al (10) and Polascik et al (15) . Miannay et al also found laparoscpic technique was significantly less painful than open one but with different method for pain assessment according to type of and doses of analgesic given (11). Mais et al found that post operative pain is mainly dependent on skin incision rather than operative procedures done, that explains why laparoscopic approach is significantly less painful in most studies. (12)

Regarding the incidence of
intraoperative
complications, no statistically significant difference was detected in both groups. That coincides with most of literatures as Ankardal et al, Bulent et al, Walter et al and Miannay et al. $(11,13,14,16)$. Kitchener et al found that bladder injury is insignificantly higher in laparoscopy group (2.8\%) than open group $(0.7 \%)$ and wound infection is significantly higher in open one. (18) In our study there were no major intraoperative or postoperative complications. One case of bladder injury recorded in laparoscopic group $(3.3 \%)$ while approaching retropubic space and repaired laparoscopically with two interrupted sutures. 3 cases of superficial wound infection were detected, 2 cases in open group (6.7\%) and one case in laparoscopic group (3.3\%). All were managed with suture removal and regular dressing.

As shown in table (5) Although post operative urinary problems were more in group B, but still no significant difference between both groups. There was no significant difference in the incidence of urgency for the laparoscopic procedure $(13.3 \%)$ compared with open procedure $(10 \%)$.and that coincides with the study by Lavin et al,of which the incidence was $6 \%$ following laparoscopic colposuspension compared with $7.6 \%$ for open surgery at 6month follow-up(19). also Carey et al recorded no significant difference between both groups(10). In our study 7 cases suffered post operative urgency. Which were mostly mixed incontinence undiagnosed by cilinical and urodynamic assessment preoperatively. 3 cases noticed in open group ( $10 \%)$ and 4 cases in laparoscopy group $(13.3 \%)$ at one month follow up . filling cystometry was done to confirm presence of detrosur overactivity . Antimuscarinic was given ( solifenacin) $5 \mathrm{mg}$. 3 months later the condition improved in all cases . Regarding postoperative urine retention it was detected in 2 cases one in each group $(3.3 \%)$. And were managed by weekly appointment in outpatient clinic for catheter removal a repeat trial of voiding. Spontanous gradual improvement was noted and no additional procedures needed.

As regards objective assessment Table (6) shows no significant difference between both groups during follow up at 1, 6 and 12 months. Kitchener et al found negative one hour pad test at 6 months follow up in $84.5 \%$ of patients of open group and $85.4 \%$ in laparoscopic group. And at 12 months results was $77.6 \%$ and 80.4 respectively. Which is also insignificant between both groups. (18)

Regarding patient satisfaction there was no significant difference between both groups during follow up at 1, 6 and 12 months follow up as shown in table (7) and also no significant change noticed over time in both groups. There was some difference noticed between objective cure rate and patient satisfaction. As the later affected by other factors as hospital service, post operative urinary problems as urgency and difficult voiding. Carey et al found no significant difference regarding patient satisfaction At 24 months follow up with $70 \%$ for open group and $58 \%$ for laparoscopic group.(10) Kitchener et al recorded $58.1 \%$ for open and $66.2 \%$ for laparoscopy at 12 months. This was also insignificant. (18)

\section{REFERENCES}

1). Fantl JA, Bump RC, Robinson $D$ et al. Efficacy of estrogen supplementation in the treatment of urinary incontinence. The 
Continence Program for Women Research Group. Obstet Gynecol 1996;88(5):745-49

2) Hunskaar S, Lose G, Sykes D et al. The prevalence of urinary incontinence in women in four European countries. BJU Int 2004;93(3): 324-30

3) Abrams P, Cardozo L, Fall $M$, et al The standardization of terminology in lower urinary tract function: report from the standardisation sub-committee of the International Continence Society. Urology 2003;61(1):37-49

4) Haylen BT, de Ridder D, Freeman RM, et al. An International Urogynecological Association (IUGA)/International Continence Society (ICS) joint report on the terminology for female pelvic floor dysfunction. Neurourol Urodyn 2010; 29:4.

5) Wall LL. Urinary stress incontinence. In: Rock JA, Thompson JD, editors. TeLinde's operative gynecology. 8th ed. Philadelphia: Lippincott-Raven; 1997. p. 1087-134.

6) Burch J, Moehrer B, Carey M, et al. (1968): Cooper's ligament urethrovesical suspension for stress incontinence. American Journal of Obstetrics and Gynecology, volume 100:764774.

7) Chen Huang W and Ming Yang J (2004): Anatomic comparison between laparoscopic and open Burch colposuspension for primary stress urinary incontinence.Urology 63: 676681.

8) Vancaillie TG, Schuessler W. Laparoscopic bladder neck suspension. J Laparoendosc Surg 1991;1:169-73.

9)Gabrielle M, Katz J, Stinson J et al (2012): Validation of the Numerical Rating Scale for Pain Intensity and Unpleasantness in Pediatric Acute Postoperative Pain : Sensitivity to Change Over Time The Journal of Pain, Vol 13, No $4: 359-369$.

10) Carey M., Goh J., Rosamilia A., et al (2006): Laparoscopic versus open Burch colposuspension: a randomised controlled trial. British journal of obstetrics and gynecology; 113: 999- 1006.

11) Miannay E., Cosson M., Lanvin D., et al (1998): Comparison of open retropubic and laparoscopic colposuspension for treatment of stress urinary incontinence. European journal of obstetrics and gynecology and reproductive biology; 79: 159-166.

12) Persson J. and Hanssen P (2000): Laparoscopic Burch colposuspension for stress urinary incontinence: a randomised comparison of one or two sutures on each side of the urethra. Obstetrics and Gynecology; 95:151-154.

13) Bulent Tiras, M.; Sendag, F. and Dilek, U. et al. (2004): Laparoscopic Burch colposuspension: Comparison of effectiveness of extraperitoneal and transperitoneal techniques. European Journal of Obstetric \& Gynecology and Reproductive Biology; 116: 79-84.

14) Walter J., Abraham N., Hammer H., et al (2002): Laparoscopic versus open Burch retropubic urethropexy: comparison of morbidity and costs when performed with concurrent vaginal prolapse repairs. American Journal of obstetrics and gynecology; 186:723728.

15) Polascik T., Moore R., Rosenerg M., et al (1995): Comparison of laparoscopic and open retropubic urethropexy for treatment of stress urinary incontinence. Urology; 45: 647-652.

16) Ankardal M., Ekerydh A., Crafoord K., et al (2004): A randomised trial comparing open Burch colposuspension using sutures with laparoscopic colposuspension using mesh and staples in women with stress urinary incontinence. British Journal of Obstetrics and Gynecology; 111: 974-981.

17) Mais V, Ajossa S, Guerriero S, et al. (1996): postoperative pain and postoperative recovery following respective laparoscopy: no relation to intra-abdominal surgical procedure. Gynaecological Endoscopy;5:197-201.

18) Kitchener H., Dunn G., Reid F et al (2006): Laparoscopic versus open colposuspensionresults of a prospective randomised controlled trial. International journal of obstetrics and gynaecology.113:1007-1013.

19) Lavin JM, Lewis CJ, Foote AJ, et al. (1998): Laparoscopic Burch colposuspension: a minimum of 2 years follow-up and comparison with open colposuspension. Gynaecologic Endoscopy, volume 7:251-8. 